1 Whitley RJ, Nahmias AJ, Soong S-J, Galasso GG, Fleming CL, Alford CA. Vidarabine therapy of neonatal HSV infection. Pediatrics 1980; 66: 495-501.

2 Whitley RJ, Arvin A, Prober C, Burchett S, Corey L, Powell D, et $a l$ and the National Institute of Allergy and Infectious Diseases Collaborative Antiviral Study Group. A controlled trial comparing vidarabine with acyclovir in neonatal HSV infection. N Engl F Med 1991; 324: 444-9.

3 Nahmias AJ, Hagler WS. Ocular manifestations of herpes simplex in the newborn (neonatal herpes simplex). Int Ophthalmol Clin 1972; 12: 191-213.

4 el Azazi M, Malm G, Forsgren M. Late ophthalmologic manifestations of neonatal HSV infection. Am $\mathcal{F}$ Ophthalmol 1990; 109: 1-7.

5 Wright P, Collin JRO. The ocular complications of erythema multiforme (Stevens Johnson syndrome) and their management. Trans Ophthalmol Soc UK 1983; 103: 338-41.

6 Tseng SCG. Concept and application of limbal stem cells. Eye 1989; 3: 141-57.

\title{
Bilateral angle closure glaucoma and accelerated cataract formation in a patient with AIDS
}

\author{
Naresh Joshi, Peter H Constable, Todd P Margolis, Creig S Hoyt, Timothy J K Leonard
}

Recent reports have described the occurrence of bilateral angle closure glaucoma secondary to choroidal effusions in patients with AIDS. We report the rapid onset of cataracts in a patient with this syndrome.

\section{Case report}

A 44-year-old white man with Pneumocystis carinii pneumonitis, presented with visual deterioration over the course of 1 day. His past ocular history was unremarkable. Visual acuity on presentation was counting fingers at 1 metre in both eyes, which improved to $6 / 12$ with pinhole correction. Anterior segment examination revealed bilateral chemosis and microcystic corneal oedema. The anterior chambers were shallow, especially peripherally; the angles were closed 360 degrees in both eyes on gonioscopy. The pupils were in a mid-dilated position, and reacted to bright illumination segmentally. The intraocular pressure on applanation tonometry was $38^{\circ} \mathrm{mm} \mathrm{Hg}$ (right eye) and $36 \mathrm{~mm} \mathrm{Hg}$ (left eye). The lenses were clear and the vitreous was quiet. The retinal vasculature was tortuous and dilated, there were scattered cotton wool spots and peripheral retinal haemorrhages, consistent with HIV microvasculopathy. The ora was posteriorly displaced. Bilateral acute angle closure glaucoma was diagnosed.

Treatment was started with intravenous and oral acetazolamide therapy, and bilateral topical pilocarpine $4 \%$ and dexamethasone $0 \cdot 1 \%$. The following day the intraocular pressures remained elevated at $34 \mathrm{~mm} \mathrm{Hg}$ in both eyes. Bilateral YAG iridotomies were performed, with no appreciable change in anterior chamber depth or change in intraocular pressure. Pilocarpine was discontinued and cyclopentolate $1 \%$ therapy begun following the laser procedure. A B ultrasound scan revealed choroidal and ciliary body thickening in both eyes (Fig 1). Within the course of the next 36 hours of instituting cycloplegic therapy the anterior chambers deepened fully and the intraocular pressure decreased to 10 and $12 \mathrm{~mm} \mathrm{Hg}$. The following day his intraocular pressures were below $10 \mathrm{~mm} \mathrm{Hg}$ in both eyes and remained so subsequently. Cortical haze was noted in both lenses: the opacification continued to increase and, within a week, both lenses were completely opaque. The following week the patient underwent cataract extraction and intraocular lens insertion, with a final best corrected visual acuity of $6 / 9$ (right) and 6/6 (left). All the ocular samples removed at the time of surgery including aqueous, cortical aspirate, and the lenticular nuclei from both eyes were examined for cytomegalovirus (CMV) and HIV p24 antigens. These tests were all negative. Serological studies confirmed infection with HIV, with a CD4 count of 32. A significant fourfold rise in CMV antibody titre was detected but no CMV virus was isolated from any source.

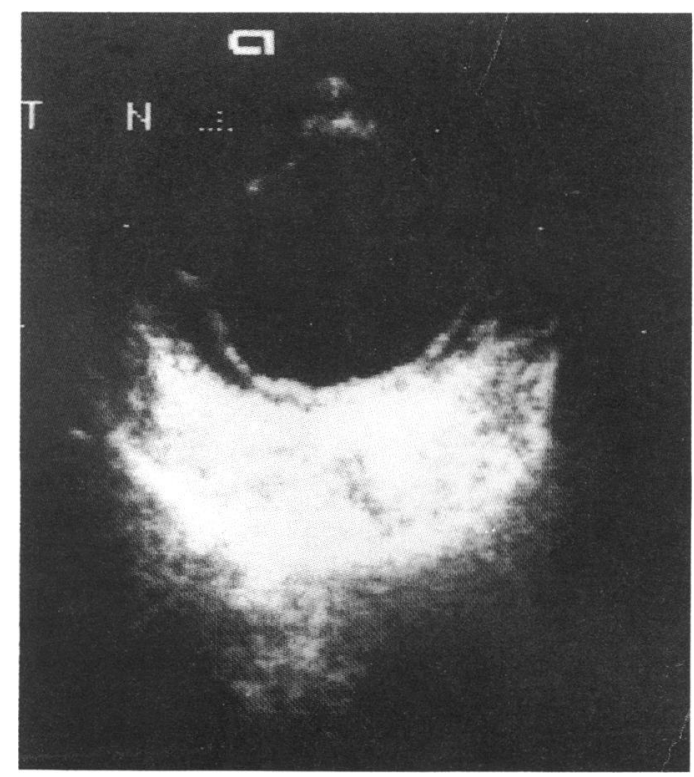

Figure 1 B scan ultrasound of left eye demonstrating annular choroidal effusion.
Correspondence to:

Ophthashi, Department

Cross Hospital, London

W6 8RF.

Accepted for publication

15 March 1994 


\section{Comment}

A number of cases of bilateral acute angle closure glaucoma associated with HIV have been reported. ${ }^{1-4}$ The mechanism of angle closure is thought to be due to anterior rotation of the irislens diaphragm at the axis of the scleral spur secondary to an anterior uveal effusion. Cyclopentolate retracts the iris lens diaphragm posteriorly and therefore opens the angle. Relative pupillary block does not appear to play a role in increasing intraocular pressure; hence conventional therapies for angle closure glaucoma are ineffective. The underlying cause for the effusions is not known. Unlike the previously reported cases, this case was complicated by the formation of bilateral cortical cataracts. The underlying cause of the cataracts is not known, but the possible mechanisms include; inflammatory, infective, ischaemic, and traumatic processes. Cataract of such rapid onset after moderate inflammation is unlikely. We did not find any infectious agents in the surgical specimens. Ischaemic changes, secondary to raised pressure, tend to be regional, limited to the anterior capsule and subepithelial cortical region (glaukomflecken). Cornea-lens touch was not evident, and unlikely in this anterior chamber configuration; there was no evidence of ciliary body lens touch on ultrasonography. YAG laser iridotomies may cause lenticular damage but the rapid onset, the generalised nature, and bilaterality makes this unlikely. Bilateral angle closure glaucoma in patients with HIV infection is a recognised phenomenon that requires dilatation with cycloplegia and aqueous suppressants to reverse the attack. Argon iridoplasty ${ }^{3}$ and drainage of the effusions ${ }^{1}$ have been advocated as alternative forms of therapy. This case illustrates that bilateral angle closure glaucoma in patients with HIV may be complicated by cataracts which are amenable to conventional cataract surgery.

We thank M Restori, department of ultrasonography, Moorfields Eye Hospital, London.

1 Ullman S, Wilson RP, Schwartz L. Bilateral angle-closure glaucoma in association with the acquired immune deficiency syndrome. Am F Ophthalmol 1986; 101: 419-24.

2 Williams AS, Williams FC, O'Donnell J]. AIDS presenting as acute glaucoma. Arch Ophthalmol 1988; 106: 311-2.

3 Koster HR, Liebmann JM, Ritch R, Hudock S. Acute angleclosure glaucoma in a patient with AIDS successfully treated with argon laser peripheral iridoplasty. Ophthalmic Surg 1990; 21: 501-2.

4 Nash RW, Lindquist TD. Bilateral angle-closure glaucoma associated with uveal effusion: presenting sign of HIV infection. Surv Ophthalmol 1992; 36: 255-8.
Department of

Ophthalmology, Royal Hallamshire Hospital, Sheffield S10 2RX

P Harvey

J F Talbot

University Department of Pathology, The Medical School, Sheffield

S10 2RX

J A Lee

J R Goepel

Correspondence to: Dr J A Lee, University Department of Pathology, Hill Road, Sheffield S10 2RX. Accepted for publication 11 April 1994

Figure 1 Global $(A)$ and high power $(B)$ views of the clinical appearance of the lesion.

\title{
Isolated xanthogranuloma of the limbus in an adult
}

\author{
P Harvey, J A Lee, J F Talbot, J R Goepel
}

A 30-year-old man presented with a yellow, painless, rapidly growing, raised nodule on the superior limbus of the right eye. Histological examination showed a xanthogranuloma. We discuss the clinical features, pathogenesis, and treatment of this rare condition.

\section{Case report}

A 30-year-old man was referred to the ophthal-

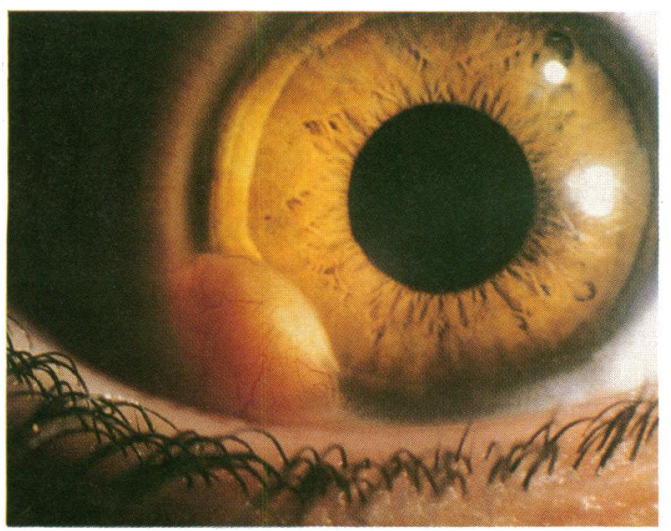

Fig IA mology clinic with a painless lesion on the superior limbus of his right eye. It had first been noticed 5 months previously, and had since rapidly increased in size and begun to encroach on the visual axis. On examination there was a well circumscribed, smooth surfaced, yellow, raised nodule at the upper temporal corneoscleral junction (Fig 1). There were no other ocular or systemic abnormalities. Excision was performed under topical anaesthesia. Surgery entailed

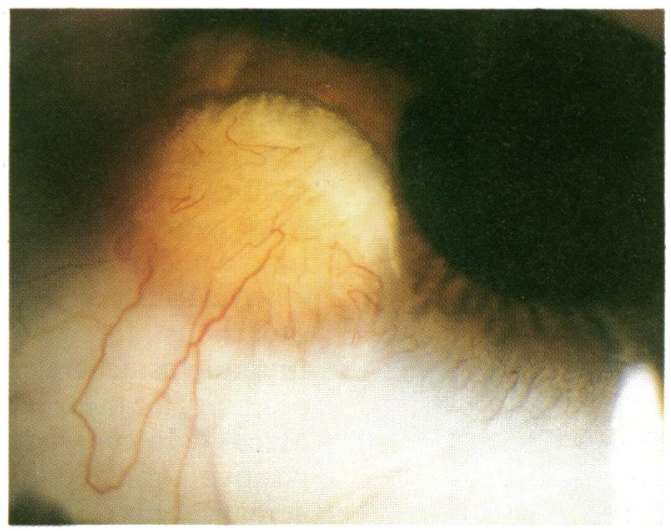

Fig IB 